\title{
Exploring the Effectiveness of Combined Web-based Corpus Tools for Beginner EFL DDL
}

\author{
Kiyomi Chujo ${ }^{1}$, Yuichiro Kobayashi ${ }^{2, *}$, Atsushi Mizumoto ${ }^{3}$, Kathryn Oghigian ${ }^{4}$ \\ ${ }^{1}$ College of Industrial Technology, Nihon University, Japan \\ ${ }^{2}$ Faculty of Sociology, Toyo University, Japan \\ ${ }^{3}$ Faculty of Foreign Language Studies, Kansai University, Japan \\ ${ }^{4}$ School of Fundamental Science and Engineering, Waseda University, Japan
}

Copyright $\bigcirc 2016$ by authors, all rights reserved. Authors agree that this article remains permanently open access under the terms of the Creative Commons Attribution License 4.0 International License

\begin{abstract}
The purpose of this study is to investigate the effectiveness of combining two newly developed web-based tools for the foreign language DDL classroom. One is a KWIC concordance tool, WebParaNews, and the other is a lexical profiling tool, the LagoWordProfiler. Both are freeware and are based on the same parallel corpus, ParaNews, which consists of newspaper texts in English along with their aligned translations in Japanese. Using the same syllabus to teach various types of noun phrases for ten weeks, only one tool was used with the 2013 group, and both of the two tools were used in combination with the 2014 group. In order to reconfirm the effectiveness of combining two tools, both of the two tools were also used in 2015 group. In each year the teaching effect was measured using a pre- and post-test, and students' feedback was collected using a 31-item questionnaire. Groups using both tools performed better than the single tool group on the gain between the pre- and post-test and gave more positive student feedback. This combined-resource approach using different types of information from two corpus tools may be more helpful for understanding the targeted grammar items than a more traditional single tool approach.
\end{abstract}

Keywords DDL, Web-based Corpus Tools, EFL

\section{Introduction}

\subsection{DDL in the EFL Classroom}

The benefits of the use of corpora and Data Driven Learning (DDL) have been well documented over the last two decades [21, 24, 33]. Through meta-analyses of DDL studies, it has been shown that DDL can be effective for learning EFL grammar and vocabulary [18, 27]. However, surveys of corpus-based ELT studies [8, 18, 34] have confirmed the widely held belief that benefits are generally limited to intermediate and advanced level learners. One possible reason concerns the difficulty students have in understanding the English concordance examples retrieved $[20,32]$. In Cobb and Boulton's [18] comprehensive empirical corpus use studies, one third of the 116 publications used large corpora such as the British National Corpus (BNC) or the Corpus of Contemporary American English (COCA). Allan [1] pointed that the BNC presents the difficulty of unfamiliar topics from everyday life, and the length of sentences. In an investigation of 64 copyright-free e-texts, according to their readability index, Chujo, et al [17, p. 67] noted that there was "an unfortunate shortage of copyright available e-texts at the beginner level." Another possible reason is the lack of user-friendly tools. Some tools try to meet the needs of both researchers and teachers and are overly complicated for students' use [3,20]. According to Tribble's recent survey among 560 language teachers and teacher educators [34], the most-used corpus programs for teaching was Mark Davies' Brigham Young University website followed by Wordsmith Tools [30] and AntConc [2]. Tribble points that for most users, the user-friendliness and free access appear to be major factors for selecting a corpus program. Unfortunately these three tools were developed for researchers and advanced learners and are too refined for general EFL students' use. In order to implement DDL in a beginner-level classroom, these two challenges, i.e. appropriate-level corpora and user-friendly corpus tools, need to be overcome.

Beginning in 2005, a series of studies were undertaken at a Japanese university showing that DDL could be effectively used with low proficiency level students $[3-4,9$, 11-16, 29]. If certain conditions were met, namely, that the corpus used was bilingual and was pre-vetted, and that students were fully supported with a mentoring approach using a clear pedagogical format [15], those studies showed evidence that a DDL approach could be beneficial for learning lexical items, basic grammar and formulaic sequences such as noun and verb phrases in Japanese EFL 
settings [27].

In the first few years of those studies, the corpus tool used was a commercial bilingual CD-ROM product called ParaConc [6], however it was found that limitations in accessing the software (because of strict licensing controls) and the necessity of complicated system settings for each use detracted from both limited classroom time and the overall experience in using DDL. In each successive year, the syllabus focusing on learning noun and verb phrases remained constant while the corpora and the pedagogical approach (observation, presentation and hypothesis formation, practice and hypothesis testing, and production) was tested. Although student gains were made each year, it was clear that a more user-friendly tool and a more relevant corpus were needed.

The purpose of the current study has been to continue to explore the most effective combination of pedagogy, corpora and corpus tools for low proficiency level EFL students. In this iteration of the previous studies, a parallel newspaper corpus called ParaNews was used, and two new web-based tools were developed and implemented, WebParaNews (WPN) [3], and the LagoWordProfiler for ParaNews (LWP) [10]. To date usually only one corpus tool has been used in each of corpus-based ELT studies. However in this current study, the effectiveness of using two tools in one DDL lesson was investigated. They are discussed in detail in the next section.

\subsection{Two Web-based Parallel Corpus Tools}

Because the use of corpora can be a powerful tool for students to use both with guidance in class and independently, it was important that we had free, web-based tools that were readily accessible in and out of the classroom. WPN, a concordance tool, is shown in the screenshot in Figure 1. As can be seen in the figure, ten concordance lines in the target language (English) are shown with the target word or phrase aligned as the key word in context (KWIC), and corresponding translations are given below these as a reference corpus. From previous studies $[13,15]$, it was found that students are able to quickly scan the translation to confirm the specific meaning of English words or sentences, or to grasp the general meaning of the sentence. Students indicated that this is because words often have multiple and/or idiomatic meanings or they often have no idea of the meaning. Thus students perceive the Japanese translation as a sense of security. Confirming that concordance lines with Japanese translations are not overwhelming for learners, then students can focus their attention on the English concordance lines, enabling learners to be able "to formulate and test their own hypotheses about language behaviour" [23, p. 108] and they can create a hypothesis about the grammatical or lexical strings. It is possible to sort right and left to highlight aspects of a string, and the number of target concordance lines can be adjusted. A student would type in a search term, for example society, and be able to view patterns in various contexts and then draw conclusions on word usage or grammatical positioning $[7,20]$. The use of the highlighted words around the aligned KWIC "reduces the information load - especially important perhaps for lower levels" [7, p. 50]. While shown to be effective in identifying many grammatical behaviors, more extensive searching is often required to understand word behavior.

In order to better understand how words behave, a lexical profiling system is used. Figure 2 shows a screenshot of the LWP tool. In contrast to the KWIC concordance lines shown with WPN, when a word such as society is searched, the tool finds corpus-derived summaries of collocation/colligation information. In Figure 2, results for society show various types of noun phrases using society (1,769 examples); society + infinitive verbs (28 examples); and society + that-clauses (28 examples). The box in Figure 2 shows adjective + society ( 485 examples), and on the right, one can view complete example sentences (rather than truncated KWIC concordance lines) for international society in both English and Japanese. A student could potentially form a hypothesis about the use of a word from the concordance lines using WPN and confirm the hypothesis by viewing clear sentence examples from a list of grammatical categories with LWP.

To promote a DDL approach in EFL classrooms, user-friendly, free, bilingual tools and free large-scale parallel corpora are indispensable. The WPN is the first tool equipped with such a corpus. These tools and the corpus used in the tools were developed specifically for use in lower proficiency level DDL university classes. This study was designed to investigate in what way they might be best used to support students in their hypothesis formation and testing. More specifically, the research question focused on whether WPN is best used independently, or in combination with LWP. 


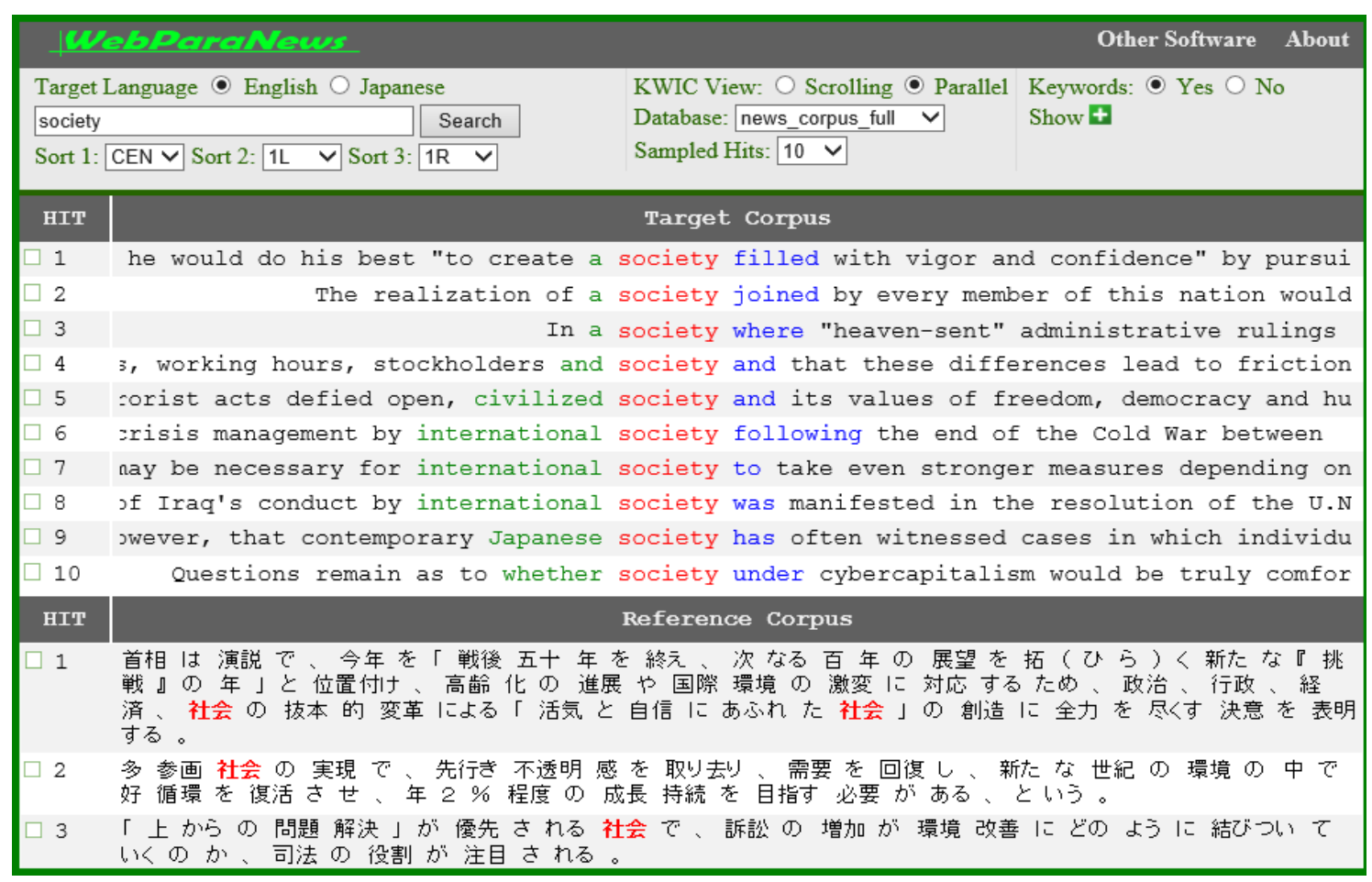

Figure 1. WPN showing general patterns of society



Figure 2. LWP showing a comprehensive analysis of how the word society behaves

\section{The Three-year DDL Study}

\subsection{Participants and Goals of Each Year}

The participants were three groups of freshmen engineering students attending the same Japanese university in 2013,2014 , and 2015. They were majoring in mechanical engineering. Each year we have only one mechanical engineering class. Thus this study took three years since we needed to have three homogeneous groups in order to compare the effectiveness of corpus tools. The majority of students were male, Japanese, aged 19. All groups met weekly for 90 minutes in a computer room for one semester for a compulsory English course. All groups followed the same syllabus and pedagogy except with regard to corpus tools used. 
The 2013 students comprised the "single tool" group (Group 1) and had 42 students including two female students. These 2013 Group 1 students used only one concordance tool, WPN. The average Test of English for International Communication (TOEIC) Bridge (TB) test score was 135 (of 180), which is equivalent to a CEFR A2 level (basic user level). The 2014 students (Group 2) had 48 participants, including three female students, and had a similar basic user level of TB 133 (of 180). The 2014 Group 2 was "double tool" group and used WPN and LWP in combination. The 2015 students (Group 3) had 39 students, including one female student, and an average TB of 140 (of 180). This 2015 Group 3 was also a "double tool" group and used WPN and LWP in combination in order to reconfirm the effectiveness of the double tools. In empirical studies, repeated observation is important.

\subsection{Parallel Newspaper Corpus}

ParaNews is based on Japanese-English News Article Alignment Data, developed by Utiyama and Isahara [36]. It is comprised of 150,000 sentence pairs from the Japanese language Yomiuri Shimbun (having 6.1 million Japanese morphemes) and the English language Daily Yomiuri (having 4.9 million English words), and these pairs are automatically aligned. In a previous study, Chujo, Utiyama, and Nishigaki [17] showed that the level of the newspaper texts is considered "Level III (difficult)" in both English and Japanese and is suitable for advanced level learners. To date there have been no English and Japanese parallel corpora available as large as ParaNews. Therefore we've tried to reduce the difficulty of the texts by controlling the difficulty of tasks, and we have taken Aston's advice [5, pp. 43-44] for choosing and grading appropriate tasks. These are described in detail in Chujo, Utiyama, and Miura [16], and summarized as choosing: (1) easy tasks which require a relatively superficial interpretation of the data; (2) tasks which lead to precise and not misleading answers; (3) simple tasks which require one search and limited manipulation of the output in order to categorize and sort citations; (4) tasks which yield an appropriate and manageable quantity of data to be analyzed; (5) tasks which yield few or no irrelevant citations; and (6) the DDL conducted in this study is pair-based so that students can help and support each other.

Furthermore this parallel corpus is particularly useful for expanding lexical knowledge important to improve students' TOEIC scores. For example, suppose that the meaning of the word file that the teacher wants to teach is not the noun as in a paper file, or the adverbial phrase single file but the verb to sue. The advantage of using a newspaper corpus is that when looking at 100 samples provided at random for file, 92 percent are used as verbs to sue and they are given in the targeted or similar context in the newspaper corpus as in to file a request and to file a lawsuit.
By having English concordancing lines together with their Japanese translations, beginner level students can understand what they are seeing. The merits of this corpus are: (1) the Japanese lines provide a general understanding of the meaning of the English concordance lines so that students can focus on the targeted grammar. Thus, "learners can focus attention on a limited and hence controlled amount of data and the input becomes more manageable" $[22$, p. 8]; (2) the contexts often refer to Japanese people or issues with which students are generally familiar because even with just a few key words, students can often understand the wider context because they are familiar with the back story, such as Japanese politics or diplomatic relationships; (3) most of the vocabulary used in this corpus is relevant to the type of general non-technical vocabulary such as that appearing in TOEIC tests and which is targeted at this university level [15]; and (4) 150,000 English and Japanese sentence pairs provide a sufficient number of example sentences for various search needs.

\subsection{Syllabus}

Table 1 shows the syllabus and tools used in this three-year study. The syllabus focused on noun phrases (hereafter NPs) which are an intrinsic element of English, and are one of the most often appearing grammatical structures in practical English expressions found in TOEIC tests. Uchibori, Chujo, and Hasegawa [35] compared grammatical structures found in TOEIC tests with those taught in secondary school textbooks. They found that secondary-level texts lacked noun phrases (NPs) and verb phrases, which are prevalent in TOEIC tests. For example, in Kanatani [25], it is pointed out that Japanese students tend to have difficulty understanding phrase structures such as a book on the desk. Students have difficulty understanding the grammatical relationship between the head noun (book) and the prepositional phrase modifying it (on the desk). It is clear that Japanese students' high school English textbooks do not prepare them for these types of grammatical structures, and it may be that they are not addressed at all. Because phrases are an integral element of English, to bridge this gap, the DDL syllabus was designed to teach NPs. The series of DDL studies at this university dating back to 2009 [11] have been designed to teach noun phrases starting with word classes, derivations and inflections, and then moving on to the structure of various noun phrases. The same syllabus was used, and the same grammar items were taught by the same teacher in the same number of hours of instruction with the same number of tasks for these three groups. As shown in Table 1, only the tools were different between the 2013 single tool group and the 2014 and 2015 double tool groups. The 2013 single tool group used the WPN tool during all ten lessons. On the other hand, the 2014 and 2015 double tool groups used the WPN tool during the first, second, eighth, ninth and tenth lessons, and both WPN and LWP tools from the third to the seventh lessons. 
Table 1. Syllabus and tools used in this study

\begin{tabular}{|c|c|c|c|}
\hline \multirow{2}{*}{ Grammar Items } & \multicolumn{2}{c|}{ Tools Used } \\
\cline { 3 - 4 } & 2013 & 2014 \& 2015 \\
\hline 1 & Word classes & WPN & WPN \\
\hline 2 & Derivations and inflections & WPN & WPN \\
\hline 3 & $\begin{array}{c}\text { NP: Determiner (Det) }+ \\
\text { adjective (Adj) + noun (N) }\end{array}$ & WPN & WPN \& LWP \\
\hline 4 & $\begin{array}{c}\text { NP: Det +N + prepositional } \\
\text { phrase (PP) }\end{array}$ & WPN & WPN \& LWP \\
\hline 5 & NP: Det +N + -ing & WPN & WPN \& LWP \\
\hline 6 & NP: Det +N + -ed & WPN & WPN \& LWP \\
\hline 7 & NP: Det +N + to-infinitive & WPN & WPN \& LWP \\
\hline 8 & $\begin{array}{c}\text { NP: Det +N + who, which, } \\
\text { that }\end{array}$ & WPN & WPN \\
\hline 9 & NP: Det +N + whose, whom & WPN & WPN \\
\hline 10 & Various NPs & WPN & WPN \\
\hline
\end{tabular}

\subsection{Classroom Procedures}

All groups followed the syllabus shown in Table 1 using the four-stage DDL approach shown in Table 2 developed by Chujo and Oghigian [15] and Chujo, et al. [13] "to incorporate cognitive processes such as noticing and hypothesis formation" [21, p. 21]. In Stage 1, students were given a worksheet with specific inductive corpus-based tasks developed by the teacher. Generally students explored six tasks in a specific grammar context using the DDL approach and employing the corpus tool. For these tasks, students worked in pairs and discussed their hypotheses as they examined the concordance lines, sharing their discoveries and offering each other support, eventually arriving at hypotheses about the form and usage of a particular grammar pattern. As easily can be seen, the DDL class procedure is similar to a traditional EFL grammar class in which the teacher first presents a grammar point, then explains it explicitly, and finally asks students to practice and produce it. The difference is that in the DDL approach, students are active in observing the data shown on their computer screens and trying to find a certain grammatical pattern from what they are seeing while in the traditional approach the teacher is active. In this stage the role of the teacher is to encourage students to notice grammatical patterns while they form hypotheses about what they are seeing in the concordance lines. Students' working in pairs is another difference from the traditional EFL approach. This paired discovery has several advantages such as 1) avoiding lone students who are lost and become silent; 2) discussing hypotheses with each other and enhancing better hypotheses; and 3) since they worked together for hypothesis formation, they are in a better position to produce language patterns at Stage 4 .

Table 2. Four-stage grammar teaching procedure

\begin{tabular}{|c|l|}
\hline $\begin{array}{c}\text { Stage } \\
1\end{array}$ & $\begin{array}{l}\text { Hypothesis formation through inductive DDL tasks with } \\
\text { hands-on WPN (and LWP) }\end{array}$ \\
\hline $\begin{array}{c}\text { Stage } \\
2\end{array}$ & $\begin{array}{l}\text { Explicit explanations from the teacher to confirm or correct } \\
\text { these hypotheses }\end{array}$ \\
\hline $\begin{array}{c}\text { Stage } \\
3\end{array}$ & $\begin{array}{l}\text { Hypothesis testing through follow-up exercises (homework) } \\
\text { and teacher feedback on homework }\end{array}$ \\
\hline $\begin{array}{c}\text { Stage } \\
4\end{array}$ & $\begin{array}{l}\text { Production through follow-up exercises (in class) and teacher } \\
\text { feedback on homework }\end{array}$ \\
\hline
\end{tabular}


WPN で lawyer を検索して空欄をうめよう。

\begin{tabular}{|c|c|}
\hline 1 & A lawyer acting as judge is unthinkable in a society \\
\hline 2 & ג such hideous crimes as killing a lawyer and his family, carrying out a sarin attack \\
\hline 3 & Isao Okamura, a lawyer representing an association of crime victims \\
\hline 4 & zy, Tamon dreamed about becoming a lawyer when as a middle school student he read \\
\hline 5 & It 1 million yen from the arrested lawyer Yasuji Yagi, 56. \\
\hline 6 & Eirst step forward," said Barugo's lawyer Hiroko Matsugi. \\
\hline 7 & E them have no lawyers or only one lawyer in their jurisdictions. \\
\hline 8 & The lawyer said he had received answers from seven or \\
\hline 9 & yangsters with the help of a woman lawyer and police. \\
\hline 10 & apping of the family of a Yokohama lawyer in 1989. \\
\hline
\end{tabular}

\begin{tabular}{|c|c|c|c|}
\hline & Pre-modifier & Head Noun & Following Elements \\
\hline 1 & $(A)$ & (lawyer) & acting as judge \\
\hline 2 & (a) & (lawyer) & $\ldots$ \\
\hline 3 & (a) & (lawyer) & representing an association of ... \\
\hline 4 & (a) & (lawyer) & $\ldots$ \\
\hline 5 & (the arrested) & (lawyer) & Yasuji Yagi \\
\hline 6 & (Barugo's) & (lawyer) & Hiroko Matsugi \\
\hline 7 & (only one) & (lawyer) & in their jurisdictions \\
\hline 8 & (The) & (lawyer) & $\ldots$ \\
\hline 9 & (a woman) & (lawyer) & $\ldots$ \\
\hline 10 & (a Yokohama) & (lawyer) & in 1989 \\
\hline
\end{tabular}

Figure 3. Example of a WPN exercise 


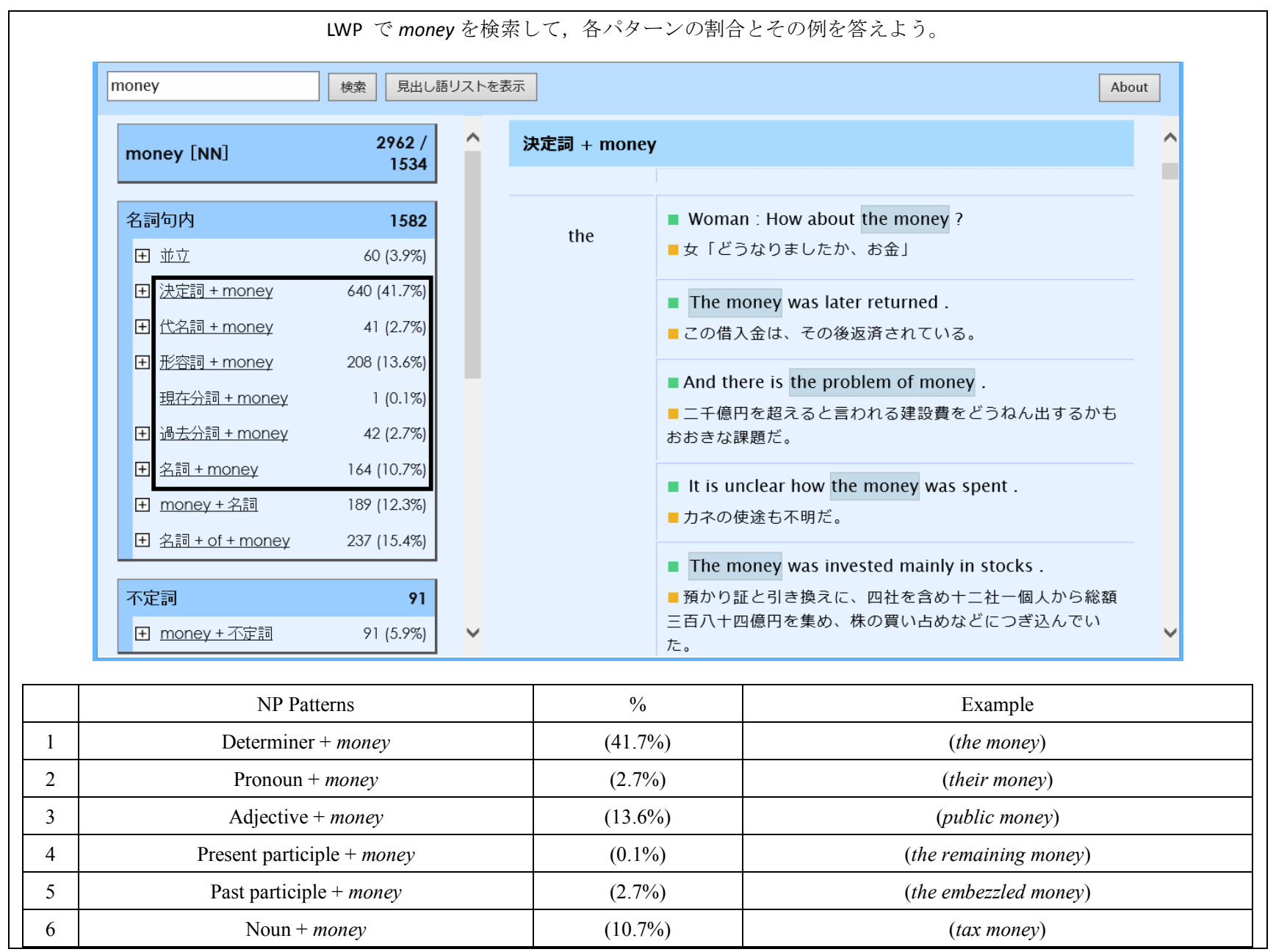

Figure 4. Example of an LWP task

An example WPN task is shown in Figure 3. The 2014 single group (1) completed six DDL tasks using only WPN. The Japanese instructions at the top of the page read "Using WPN locate lawyer and fill in the blanks." The WPN screenshot and the fill-in-the-blank answers are provided for the reader. Students learned to identify pre-modifiers such as articles, adjectives, genitives and numerals, and post-modifiers (following elements) such as present participles and prepositional phrases. From this kind of task, students begin to see that there are patterns, and to discern what the patterns are. One common error made by students is the lack of articles; this type of concordance analysis allows students to notice whether or not there is an article, what the article is, and that an adjective such as arrested and a noun such as woman appears between the article and head noun (e.g., the arrested lawyer; a woman lawyer).

In the same way, the 2014 and 2015 double tool groups (2 and 3) worked on the identical tasks with WPN for the first two and the last three weeks; however, for the middle five weeks they also did a certain number of tasks for exploring the same grammar items using LWP rather than only WPN. The total number of DDL tasks consistently remained at five to six. An example LWP task is shown in
Figure 4. The Japanese instruction reads "Using LWP, search money, find the patterns and fill in the blanks; write the corresponding percentage and an NP example representing each pattern." Students would find the results shown in the screenshot and locate the six patterns given in the table. (In the screenshot, patterns are outlined with a box, and the fill-in-the-blank answers are shown for the reader.) Students then click on a pattern in the left column, which would show example sentences in the right column with the pattern highlighted, such as the money. From this, students confirm various NP patterns with pre-modifiers such as articles, pronouns, adjectives, present participles, past participles, and nouns, and write down one phrase from each group of example sentences. By viewing percentages students learn that certain patterns appear very often and others do not. These example sentences are purposefully organized with the easier (shorter) sentences listed at the top with translations.

In Stage 2, the teacher provided an explicit explanation of the grammar items in the L1 (Japanese) so that students could confirm or correct those hypotheses they made through the previous corpus activities. In order to show the general structure of the NP, the diagram shown in Figure 5 
was repeatedly presented by the teacher through the whole course. In Figure 5, the parentheses indicate that those words are optional. After forming a hypothesis by completing the DDL tasks, and confirming or correcting the hypothesis, the next is the internalization phase to promote the hypothesis testing process. In Stage 3 they were given a one-page follow-up homework assignment to practice and consolidate grammar items. In Stage 4, they completed production practice exercises as homework. A sample of follow-up exercises is shown in Figure 6. Example Tasks 1 and 2 are consolidation exercises and Example Tasks 3 and 4 are for production exercises.

\begin{tabular}{|llll|}
\hline (Determiner) & (Adjective) & Head Noun & (Postmodifier) \\
Article & adjective & & prepositional phrases \\
quantifier & -ing & & -ing/-ed \\
numeral & -ed & & relative clauses \\
\hline
\end{tabular}

Figure 5. Grammar explanation used for introducing the general structure of the NP

Task 1. Circle a head noun and underline a noun phrase for each sentence. Look at the people waiting in line in front of the restaurant.

Task 2. Search $\boldsymbol{a} *$ store using WPN and write two NPs. a convenience store in Konohana Ward, a pilot store in Mitaka

Task 3. Complete the following English sentence. 月面を歩いた最初の人間は Neil Armstrongでした。

(The first man who walked on the moon) was Neil Armstrong.

Task 4. Write your own ending to the sentence.

Chiba is (example answer: Chiba is a good place to live.)

Figure 6. Example of follow-up exercises

\subsection{Evaluation}

Three different types of test questions to evaluate comprehension and the production of noun phrases were used and are shown in Table 3. These are (1) producing a simple NP using high frequency (easy) vocabulary; (2) identifying an NP using higher (TOEIC) level vocabulary; and (3) understanding a complex (TOEIC-type) NP. The third TOEIC-type NP questions are complex and require learners to bring together knowledge of more than one aspect of grammar (see 3.1 for a detailed explanation). Each NP test consisted of fifteen questions: five questions for three NP patterns: (1) determiner + adjective + noun; (2) determiner + noun + prepositional phrase; and (3) determiner + adjective + noun + to/-ing/-ed. Each test question was controlled by word level (a high frequency word or TOEIC level word), NP structural pattern (the above three patterns), and sentence length (average sentence length: 9.1 words, average NP length: 4.5 words). The highest possible score was 60. Partial credit was possible for producing an NP (i.e., 0, 1, or 2 points were possible), and 0 or 1 was given for the other two types of NP questions.
A pre-test was given on the first day of each course, and a post-test was given on the last day. The same pre- and post- tests were used for each group, but the order of the questions of the pre- and post- tests was changed, the students were not given the answers at any time, and the students were not told they would be given tests in advance. Research has shown that due to the time interval and because students are not given the correct answers at any time, using the same test does not impact the end results [31].

Table 3. Sample pre- and post-test questions (answers provided in bold)

\begin{tabular}{|c|l|}
\hline $\begin{array}{c}1 . \\
\text { Producing } \\
\text { NPs }\end{array}$ & $\begin{array}{l}\text { Complete the sentence. } \\
\text { (These American coins) are very old. } \\
\text { (これらのアメリカのコインは大変古いです。) }\end{array}$ \\
\hline $\begin{array}{c}\text { Identifying } \\
\text { NPs }\end{array}$ & $\begin{array}{l}\text { Underline the noun phrases. } \\
\text { We will arrange a meeting with Ms. Tanaka as soon } \\
\text { as possible. }\end{array}$ \\
\hline 3. & $\begin{array}{l}\text { Choose the best answer. } \\
\text { Most hotels offer many tours. } \\
\text { TOEIC-type } \\
\text { NPs }\end{array}$ \\
$\begin{array}{l}\text { (A) organize, (B) organizer, (C) organized, } \\
\text { (D) organizationally }\end{array}$ \\
\hline
\end{tabular}

In addition to investigating the learning gains with the pre- and post- tests, learners' general feedback on classroom tasks and attitudes toward using the tools were examined. Using a six-point rating scale from "not at all true for me" (rating 1) to "very true for me" (rating 6), a 31 -item questionnaire was administered at the end of the course [28]. In this, 13 items addressed general feedback on grammar tasks in the classroom and 18 items queried the learners' preferences. In addition, we collected open-ended reflective general comments on the tasks from all groups.

\section{Results and Discussion}

\subsection{Student Scores for the Three Types of NP Questions}

The scores among the three groups and among the three types of NP questions are shown in Table 4. The mean and standard deviation (SD) for pre-test scores and post-test scores, and effect sizes are shown for the three types of NP questions and for the three groups. Pre- and post-test score is expressed as a percentage in this table for ease of visual comparison. The Kolmogorov-Smirnov test showed distributions for each test (i.e., pre-tests and post-test of both groups) as normal. Thus, we looked at the score difference and applied a paired $t$-test (with Bonferroni's correction) to each pre- and post-test score for each NP question type and each group. There was a statistically significant increase in all types of NP questions except for the TOEIC-type NP questions for Group 1, the 2013 single tool group. The effect size for the producing and identifying NP questions was large in Group 2 (2014 double tool group) and Group 3 (2015 double tool group) or medium in Group 1 (single tool group). (For criteria, see Cohen [19]). Among these three NP questions, the results show that all 
participants improved in the "Producing NP" and "Identifying NP" questions. It is important to note that "Producing NP" and "Identifying NP" questions target a single grammar issue, i.e. "Producing an NP" focusing on the structure of an NP, that is, "determiner + adjective + noun" such as these American coins, or "Identifying an NP" focusing on a structure of an NP that is "determiner + noun + prepositional phrase" such as a meeting with Ms. Tanaka. In contrast, the "TOEIC-type NP" questions are more complex and present learners with more difficult questions. In order to answer this type of question, one must have knowledge of multiple grammar issues of how the elements within a phrase are grammatically related to one other, particularly to the head noun. In this example, the correct answer is (C):

\section{Most hotels offer many __ tours.}
(A) organize,
(B) organizer,
(C) organized,
(D) organizationally

Learners must first recognize that the blank space must be filled by an adjective, knowing that is linked to the knowledge of the structure of an NP where an adjective may appear between a determiner and a noun. Furthermore, in order to eliminate incorrect answers, they must also possess the knowledge of past participles derived from verbs behave similarly to adjectives (e.g., a broken vase), many adverbs end in $-l y$, and some nouns have identifiable noun endings such as -er. Integrating these separate pieces of knowledge about different categories into a unified knowledge of phrase structure allows learners to choose the correct answer.

Table 4. Student scores (\%) for the three types of NP questions

\begin{tabular}{|c|c|c|c|c|c|c|}
\hline \multirow[b]{2}{*}{ Group } & \multirow[b]{2}{*}{$n$} & \multirow{2}{*}{$\begin{array}{c}\mathrm{NP} \\
\text { questions }\end{array}$} & Pre-test & Post-test & \multirow[b]{2}{*}{ Gain } & \multirow{2}{*}{$\begin{array}{c}\text { Effect } \\
\text { size } \\
r\end{array}$} \\
\hline & & & $\begin{array}{c}\text { Mean } \\
(S D)\end{array}$ & $\begin{array}{c}\text { Mean } \\
(S D)\end{array}$ & & \\
\hline \multirow{3}{*}{$\begin{array}{c}(1) \\
2013 \\
\text { Single } \\
\text { Tool }\end{array}$} & \multirow{3}{*}{42} & $\begin{array}{c}\text { Producing } \\
\text { NP }\end{array}$ & $\begin{array}{c}54.4 \\
(18.6) \\
\end{array}$ & $\begin{array}{c}61.4 \\
(16.6) \\
\end{array}$ & $7.0^{*}$ & .37 \\
\hline & & $\begin{array}{c}\text { Identifying } \\
\text { NP }\end{array}$ & $\begin{array}{c}58.7 \\
(25.0)\end{array}$ & $\begin{array}{c}74.8 \\
(17.9)\end{array}$ & $16.1^{*}$ & .58 \\
\hline & & $\begin{array}{c}\text { TOEIC-type } \\
\text { NP } \\
\end{array}$ & $\begin{array}{c}51.7 \\
(14.2)\end{array}$ & $\begin{array}{c}51.1 \\
(17.0) \\
\end{array}$ & -0.6 & .05 \\
\hline \multirow{3}{*}{$\begin{array}{c}(2) \\
2014 \\
\text { Double } \\
\text { Tool }\end{array}$} & \multirow{3}{*}{48} & $\begin{array}{c}\text { Producing } \\
\text { NP }\end{array}$ & $\begin{array}{c}50.8 \\
(16.6) \\
\end{array}$ & $\begin{array}{c}67.3 \\
(15.4) \\
\end{array}$ & $16.5^{*}$ & .66 \\
\hline & & $\begin{array}{c}\text { Identifying } \\
\text { NP }\end{array}$ & $\begin{array}{c}53.5 \\
(22.1) \\
\end{array}$ & $\begin{array}{c}83.6 \\
(13.5) \\
\end{array}$ & $30.1^{*}$ & .82 \\
\hline & & $\begin{array}{c}\text { TOEIC-type } \\
\text { NP }\end{array}$ & $\begin{array}{c}50.6 \\
(15.5)\end{array}$ & $\begin{array}{c}56.0 \\
(16.6)\end{array}$ & $5.4^{*}$ & .33 \\
\hline \multirow{3}{*}{$\begin{array}{c}(3) \\
2015 \\
\text { Double } \\
\text { Tool }\end{array}$} & \multirow{3}{*}{39} & $\begin{array}{c}\text { Producing } \\
\text { NP }\end{array}$ & $\begin{array}{c}54.2 \\
(19.6)\end{array}$ & $\begin{array}{c}68.0 \\
(15.4)\end{array}$ & $13.8^{*}$ & .73 \\
\hline & & $\begin{array}{c}\text { Identifying } \\
\text { NP } \\
\end{array}$ & $\begin{array}{c}60.2 \\
(24.8) \\
\end{array}$ & $\begin{array}{c}92.0 \\
(11.5) \\
\end{array}$ & $31.8^{*}$ & .81 \\
\hline & & $\begin{array}{c}\text { TOEIC-type } \\
\text { NP }\end{array}$ & $\begin{array}{c}58.3 \\
(14.9) \\
\end{array}$ & $\begin{array}{c}63.6 \\
(15.4) \\
\end{array}$ & $5.3^{*}$ & .45 \\
\hline
\end{tabular}

Note: $* p<.05$. Accepted criteria for effect size $r$ : 0.1 (small), 0.3 (medium), 0.5 (large) [19].

Regarding the "TOEIC-type NP" questions, the effect size of Group 1 was marginal and those of Groups 2 and 3 were medium. From these results we see that Groups 2 and 3 using a double tool did better than Group 1 using a single tool.

\subsection{Scores by Type of Tool}

In order to further highlight the score differences between the single tool group (1) and the double tool groups (2 and 3 ), their raw scores (not as a percent) were compared. The full score was 60 . The results are shown in Table 5. The single tool group (Group 1) gained an average of 4.4 points from 32.9 to 37.3; and the double tool groups (Groups 2 and 3 ) gained an average of 10.0 points from 31.5 to 41.5 . The effect size $d$ of the single tool group was $0.54,95 \%$ CI $[0.26$, $0.82], p<.001$, and the effect size $d$ of the double tool groups was $1.40,95 \%$ CI $[1.17,1.64], p<.001$. Thus the effect size of the double tool was very large, and that of the single tool was medium. The Cronbach's $\alpha$, an internal consistency estimate of reliability of test scores for the pre-test, was .73, and .72 for the post-test, suggesting both test scores were relatively reliable. Thus we can say that both groups improved in terms of pre- and post-test scores, and the double tool group made greater gains.

Table 5. Student scores for the two types of DDL approaches

\begin{tabular}{|c|c|c|c|c|c|c|c|}
\hline \multirow[b]{2}{*}{ Group } & \multirow[b]{2}{*}{$n$} & \multicolumn{2}{|c|}{ Pre-test } & \multicolumn{2}{|c|}{ Post-test } & \multirow{2}{*}{$\begin{array}{l}\text { Gain } \\
(S D)\end{array}$} & \multirow{2}{*}{$\begin{array}{c}\text { Effect } \\
\text { size } d \\
{[95 \% \mathrm{CI}]}\end{array}$} \\
\hline & & $\begin{array}{c}\text { Mean } \\
(S D)\end{array}$ & $\alpha$ & $\begin{array}{c}\text { Mean } \\
(S D)\end{array}$ & $\alpha$ & & \\
\hline $\begin{array}{c}\text { Single } \\
\text { Tool }\end{array}$ & 42 & $\begin{array}{l}32.9 \\
(8.4)\end{array}$ & \multirow{2}{*}{.73} & $\begin{array}{l}37.3 \\
(7.9)\end{array}$ & \multirow{2}{*}{.72} & $4.4(6.9)$ & $\begin{array}{c}0.54 \\
{[0.26,} \\
0.82]\end{array}$ \\
\hline $\begin{array}{c}\text { Double } \\
\text { Tool }\end{array}$ & 87 & $\begin{array}{l}31.5 \\
(7.5)\end{array}$ & & $\begin{array}{l}41.5 \\
(6.8)\end{array}$ & & $\begin{array}{l}10.0 \\
(5.6)\end{array}$ & $\begin{array}{r}1.40 \\
{[1.17,} \\
1.64] \\
\end{array}$ \\
\hline
\end{tabular}

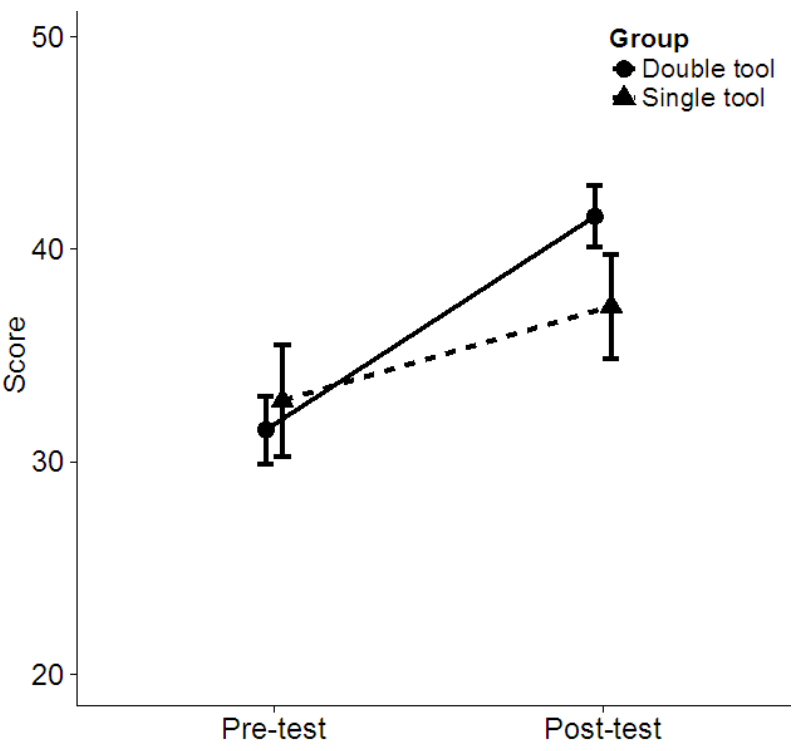

Figure 7. Results for the two types of tools (Error bars how 95\% CI)

Since there is a slight difference in the pre-test scores between the two groups, a one-way analysis of covariance (ANCOVA) was conducted to determine if there was a 
statistically significant difference between the singe tool group and the double tool groups on test scores controlling for their pre-test scores. As shown in Figure 7, the double tool groups had much greater gains than the single tool group. There is a significant effect of using a double tool on the improvement of test scores after controlling for pre-test scores, $F(1,126)=25.89, p<.001, \eta 2[95 \% \mathrm{CI}]=.10$ $[.03, .23]$.

\subsection{Participants' Responses}

Table 6 shows the results of the first 13 items (Q.1 to Q.13) regarding general feedback on classroom tasks. The mean scores of the ratings and $S D$ s are shown for the single tool group and double tool group. Data for Groups 2 and 3 (2014 and 2015) was combined and is shown as "double tool". The double tool group evaluated this grammar course higher in 11 items out of 13, and both groups evaluated them equally on two items. We can see that the double tool group not only obtained a higher learning effect but also reported they were generally more satisfied with the grammar activities compared to the single tool group.

Table 6. Participant evaluations on the classroom tasks (originally in Japanese)

\begin{tabular}{|c|l|c|c|}
\hline & \multicolumn{1}{|c|}{ Questions } & Single Tool & Double Tool \\
\cline { 3 - 4 } & & Mean $(S D)$ & Mean $(S D)$ \\
\hline Q.1 & I was able to improve my English ability. & $3.7(1.2)$ & $4.2(0.9)$ \\
\hline Q.2 & They were useful for learning grammar. & $4.0(1.2)$ & $4.3(1.0)$ \\
\hline Q.3 & The learned grammar was easily fixed in my memory. & $3.6(1.3)$ & $4.1(0.9)$ \\
\hline Q.4 & The tasks were enjoyable. & $3.7(1.4)$ & $4.0(1.2)$ \\
\hline Q.5 & The tasks suited me. & $3.2(1.4)$ & $3.7(1.3)$ \\
\hline Q.6 & I'd like to recommend the tasks to others. & $3.2(1.3)$ & $3.6(1.2)$ \\
\hline Q.7 & I had more interest in learning English through the tasks. & $3.5(1.4)$ & $3.9(1.1)$ \\
\hline Q.8 & The goal of the grammar tasks was clear. & $4.0(1.3)$ & $4.2(1.3)$ \\
\hline Q.9 & I was able to concentrate on the tasks. & $4.2(1.2)$ & $4.6(1.0)$ \\
\hline Q.10 & I was able to do the tasks at my own pace. & $4.5(1.2)$ & $4.5(1.0)$ \\
\hline Q.11 & I was able to understand the grammar items I had not known. & $3.8(1.4)$ & $3.9(1.0)$ \\
\hline Q.12 & They were helpful in understanding the target grammar items. & $4.1(1.3)$ & $4.1(1.0)$ \\
\hline Q.13 & This class was different from traditional English lessons. & $3.9(1.5)$ & $4.1(1.2)$ \\
\hline
\end{tabular}

Note: Single tool $(n=39)$ and Double tool $(n=84)$. Feedback from six participants was not included since there were a few omitted items among the responses.

Table 7. Participant evaluation on the advantages of DDL (originally in Japanese)

\begin{tabular}{|l|l|c|c|}
\hline & \multicolumn{1}{|c|}{ Questions } & Single Tool & Double Tool \\
\cline { 2 - 4 } & & Mean $(S D)$ & Mean $(S D)$ \\
\hline Q.14 & I can see many examples that include the target structure. & $5.1(0.9)$ & $4.9(1.0)$ \\
\hline Q.15 & It shows many frequently used examples. & $4.6(1.2)$ & $4.7(1.1)$ \\
\hline Q.16 & Words are displayed in an organized manner. & $4.3(1.2)$ & $4.4(1.1)$ \\
\hline Q.17 & I get to see Japanese translations. & $4.8(1.2)$ & $4.4(1.2)$ \\
\hline Q.18 & I can see the target examples in real contexts. & $4.9(1.2)$ & $4.9(0.9)$ \\
\hline Q.19 & I can visualize the practical usage. & $4.8(1.1)$ & $4.9(0.9)$ \\
\hline Q.20 & I can see such a massive quantity of examples easily. & $4.8(1.1)$ & $4.7(1.1)$ \\
\hline Q.21 & I can use software I have never used before. & $3.4(1.4)$ & $3.8(1.3)$ \\
\hline Q.22 & We don't use English textbooks; instead, we use computers. & $4.1(1.5)$ & $4.5(1.4)$ \\
\hline Q.23 & It is different from traditional or regular English learning. & $3.4(1.5)$ & $3.9(1.4)$ \\
\hline Q.24 & I can search for and learn target examples independently. & $4.2(1.3)$ & $4.5(1.2)$ \\
\hline Q.25 & This type of learning is active rather than passive. & $4.0(1.2)$ & $4.3(1.2)$ \\
\hline Q.26 & I can visualize the various word forms such as inflections and derivations. & $4.3(1.2)$ & $4.7(0.9)$ \\
\hline Q.27 & I am starting to think about what part of speech words belong to. & $3.9(1.3)$ & $4.6(1.0)$ \\
\hline Q.28 & I can see many more example sentences than in a dictionary. & $4.8(1.1)$ & $4.9(1.0)$ \\
\hline Q.29 & I can discover a usage I did not know. & $4.5(1.2)$ & $4.5(1.0)$ \\
\hline Q.30 & It shows the context where the words are often used. & $4.6(1.2)$ & $4.7(1.0)$ \\
\hline Q.31 & I was able to understand the meaning of a word from the context. & $4.7(1.1)$ & $4.7(1.0)$ \\
\hline
\end{tabular}

Note: Single tool $(n=39)$ and Double tool $(n=84)$. Feedback from six participants was not included since there were a few omitted items among the responses. 
Table 7 shows the results in six-point ratings for the next 18 items (Q.14 to Q.31) regarding the responses to perceived advantages of using DDL in general. The double tool group had higher evaluations in 12 items out of 18 . The two groups evaluated the tools equally for three items, and the single tool group had higher evaluations for three items: an ability to see many examples, having Japanese translations, and having a large number of English examples so easily viewed. It may be that the single tool group felt more strongly about the strengths of a KWIC concordancer and a parallel corpus than the double tool group, so many of them gave a 6 rating to these items. Overall again the double tool group not only obtained a higher learning effect but also gave higher scores than the single tool group. Furthermore, the results seem to suggest that these questionnaire items (Q.14 to Q.31) verified that they were an appropriate scale and a valid measure of learners' attitude toward DDL (as demonstrated in Mizumoto, et al. [28]), indicating a good fit with the learning effect data.

Figure 8 is a visualization of all 31 -item questionnaire results. This graph shows the standardized effect size $d$ from the difference (double tool score minus single tool score) with $95 \%$ confidence intervals (CI) for each item. The right side shows the double tool, and the left side shows the single tool. We can see in many items that the $95 \%$ CI bars lie toward double tool side, and we can say that the double tool mean scores tend to be higher for many items. Thus the double tool participants evaluated both the grammar course and the merits of DDL higher.

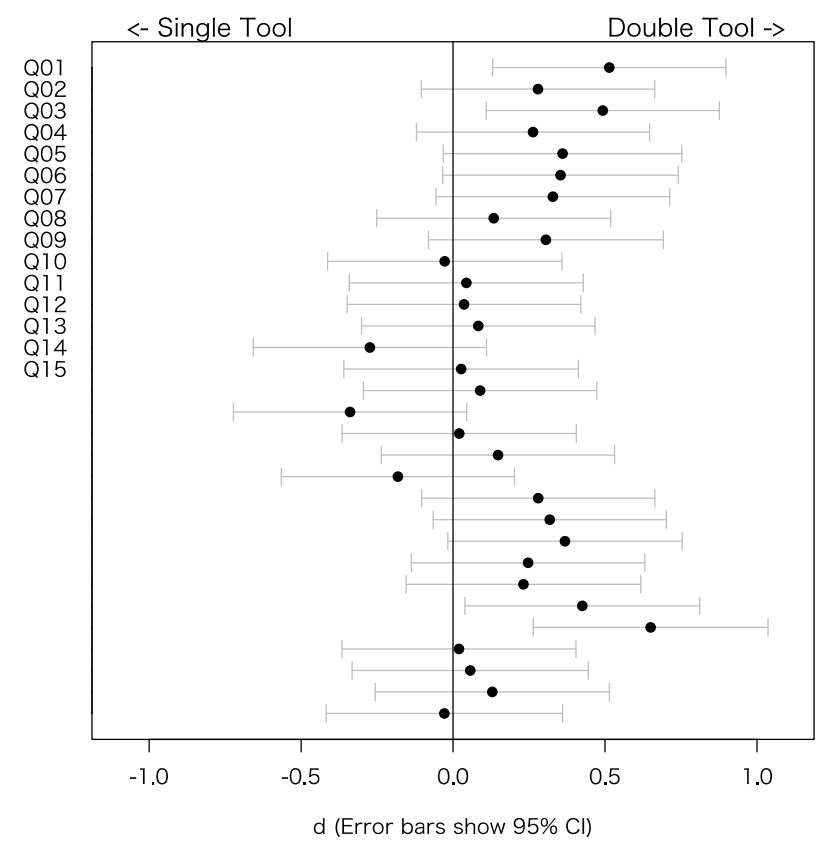

Figure 8. Visualization of participant responses for the two types of tools

Additionally, open-ended comments were collected in 2013, 2014, and 2015, and most of the comments were positive. What we were most interested in was asking Group 3 participants whether they preferred combining two tools and why or why not. All answered "yes." In their comments, originally in Japanese, 38 students out of 39 students stated clearly why they thought so, summarized here: (1) each tool has its own merit, i.e., WPN is good for grasping the rough usages while LWP is good for understanding the detailed combinations and frequency of the usage of a word (23 students out of 38); (2) complementing each tool's specialty enhances the learning more effectively (10 out of 38 ); and (3) using WPN followed by LWP deepens my understanding of the structure (5 out of 38). The participants' statements support the claim that using both tools resulted in a better learning effect compared to using a single tool.

\section{Conclusions}

In spite of the fact that the use of corpora is now more and more common for researchers, linguists, lexicographers and translators [34], the reality is that potentially powerful and effective DDL tools are not used extensively in EFL teaching practice [21] for a variety of reasons, particularly at the beginner level. Teachers and students must have access to reliable and fast computer systems (and electricity that first world nations take for granted); there must be time in a curriculum to introduce students to DDL and guide them through what it is to be a language researcher themselves [26]; complex and often overwhelming monolingual concordance lines can be countered with parallel corpora and the use of sorting; a corpus must be found that is relevant, that is, by language, age, culture, register and context, and paired with an easily accessible and user friendly corpus tool (preferably free); and finally, teachers need the experience to either anticipate problematic search results or pre-vet the searches by providing paper-based search results [12], or by controlling the corpus. Although one of the many benefits of using corpora is that both teacher and students are co-investigators and discover results in real time, for beginner or low proficiency level students, navigating complex concordance lines in English requires very carefully planned guidance. Over ten years, this series of studies has shown that the use of corpora at the beginner level is possible and can be effective. In this current study, we demonstrate that although a concordance tool such as WebParaNews (WPN) can be very useful to students, when paired with a lexical browsing tool like the LagoWordProfiler (LWP), it can be highly effective and enjoyable for students. These tools are free and available at $\mathrm{http}: / /$ www.antlabsolutions.com/webparanews and http://lpn.lagoinst.info.

Clearly when dealing with very large EFL classrooms, there can be additional variables. The next step would be to clarify the effect of using a double tool by differentiating and controlling the participants' skill levels, the class size, the type of DDL such as hands on (direct computer searches by participants) or hands off (paper-based results provided to students), and types of corpora and tools. 


\section{REFERENCES}

[1] Allan, R. (2009). Can a graded reader corpus provide 'authentic' input? ELT Journal 63(1), 23-32.

[2] Anthony, L. (2014). AntConc (Version 3.4.3) [computer software]. Tokyo: Waseda University. Available from http://www.laurenceanthony.net/

[3] Anthony, L., Chujo K., and Oghigian, K. (2011). A novel, web-based, parallel concordancer for use in the ESL/EFL classroom. In J. Newman, H. Baayen and S. Rice (Eds.), Corpus-based studies in language use, language learning, and language documentation (pp. 123-138). Amsterdam: Rodopi.

[4] Anthony, L., Chujo, K., Yokota, K., and Mizumoto, A. (2014, March). Broadening the scope of parallel corpus tools: Using AntPConc in the DDL classroom. Presentation given at Second Asia Pacific Corpus Linguistics Conference (APCLC) 2014, Hong Kong.

[5] Aston, G. (Ed.) (2001). Learning with corpora. Houston: Athelstan.

[6] Barlow, M. (2004). ParaConc [computer software]. Houston TX: Athelstan.

[7] Boulton, A. (2009). Testing the limits of data-driven learning: Language proficiency and training. ReCALL, 21(1), 37-54.

[8] Boulton, A. (2010). Data-driven learning: Taking the computer out of the equation. Language Learning, 60, 534-572.

[9] Chujo, K. (2008). Corpus-based syllabus design and its implementation. In J. Nakamura and S. Hotta (Eds.), Intersection between corpus and English language education (pp. 65-88). Tokyo: Shohakusha.

[10] Chujo, K., Anthony, L., Akasegawa, S., and Oghigian, K. (2014). Combining two corpus tools for easier and effective DDL. The abstract book of the 11th teaching and language corpora conference (TaLC), Lancaster University, UK (pp. 94-95).

[11] Chujo, K., Anthony, L., and Oghigian, K. (2009). DDL for the EFL classroom: Effective uses of a Japanese-English parallel corpus and the development of a learner-friendly, online parallel concordancer. Proceedings of 5th Corpus Linguistics Conference 2009, University of Liverpool, UK (pp. 1-15).

[12] Chujo, K., Anthony, L., Oghigian, K., and Uchibori, A. (2012). Paper-based, computer-based, and combined data-driven learning using a web-based concordancer. Language Education in Asia, 3, 132-145.

[13] Chujo, K., Anthony, L., Oghigian, K., and Yokota, K. (2013). Teaching remedial grammar through data-driven learning using AntPConc. Taiwan International ESP Journal, 5(2), $65-90$.

[14] Chujo, K., and Oghigian, K. (2007). Discovering grammar basics with parallel concordancing in the beginner-level EFL classroom. Proceedings of the 2007 Asia TEFL International Conference, Kuala Lumpur, Malaysia, 1-14.

[15] Chujo, K., and Oghigian, K. (2012). DDL for EFL beginners: A report on student gains and student views on the paper-based concordancing and the role of L1. In J. Thomas and A. Boulton (Eds.), Input, process and product: Developments in teaching and language corpora (pp. 169-182). Brno: Masaryk University Press.

[16] Chujo, K., Utiyama, M., and Miura, S. (2006). Using a Japanese-English parallel corpus for teaching English vocabulary to beginning-level students. English Corpus Studies, 13, 153-172.

[17] Chujo, K., Utiyama, M., and Nishigaki, C. (2007). Towards building a usable corpus collection for the ELT classroom. In E. Hidalgo, L. Quereda, and J. Santana (Eds.), Corpora in the foreign language classroom (pp. 47-69). Amsterdam: Rodopi.

[18] Cobb, T., and Boulton, A. (2015). Classroom applications of corpus analysis. In D. Biber and R. Reppen (Eds.), The Cambridge handbook of corpus linguistics (pp. 478-497). Cambridge: Cambridge University Press.

[19] Cohen, J. (1988). Statistical power analysis for the behavioral sciences (2nd ed.). Hillsdale: Lawrence Erlbaum.

[20] Flowerdew, L. (2012). Corpora and language education. Basingstoke: Palgrave Macmillan.

[21] Flowerdew, L. (2015). Data-driven learning and language learning theories: Whither the twain shall meet. In A. Leńko-Szymańska and A. Boulton (Eds.), Multiple affordances of language corpora for data-driven learning ( $\mathrm{pp}$. 15-36). Amsterdam: John Benjamins.

[22] Gass, S. (1997). Input, interaction, and the second language learner. Mahwah: Lawrence Erlbaum Associates.

[23] Gavioli, L. (2001). The learner as researcher: Introducing corpus concordancing in the classroom. In G. Aston (Ed.), Learning with corpora (pp. 109-137). Houston: Athelstan.

[24] Johns, T. (1991). From print out to handout: Grammar and vocabulary teaching in the context of data-driven learning. In T. Johns, and P. King (Eds.), English Language Research Journal 4: Classroom concordancing (pp. 27-46). Birmingham: Centre for English Language Studies.

[25] Kanatani, K. (Ed.) (1994). Teichaku jyuushi no eigo tesuto ho [English test method with the emphasis on stability]. Tokyo: Kagensya.

[26] Kennedy, C., and Miceli, T. (2010). Corpus-assisted creative writing: Introducing intermediate Italian learners to a corpus as a reference resource. Language Learning and Technology, 14(1), 28-44.

[27] Mizumoto A., and Chujo, K. (2015). A meta-analysis of data-driven learning approach in the Japanese EFL classroom. English Corpus Studies, 22, 1-18.

[28] Mizumoto A., Chujo, K., and Yokota, K. (2016). Development of a scale to measure learners' perceived preferences and benefits of data-driven learning. ReCALL, 28(2), 227-246.

[29] Oghigian, K, and Chujo, K. (2010). An effective way to use corpus exercises to learn grammar basics in English. Language Education in Asia, 1, 200-214.

[30] Scott, M. (2012). WordSmith Tools 6.0 [computer software]. Liverpool: Lexical Analysis Software. 
[31] Takahashi, H., Suzuki, H., and Takefuta, Y. (2003). CALL kyoozai niyoru jikogakusyuu to jyugyookatudoo o yuugoosaseta daigakusei eigo chookairyoku no yousei [An integration of CALL self-study and classroom activities for improving Japanese college learners' English listening skills]. Japan Journal of Educational Technology, 27(3), 305-314.

[32] Tian, S., and Liu, L. (2004). Course-specific corpora in the classroom: A news media English class in Taiwan. The Journal of ASIA TEFL 1(1), 267-290.

[33] Tono,Y., Satake, Y., and Miura, A. (2013). The effects of using corpora on revision tasks in L2 writing with coded error feedback. ReCALL, 26(2), 147-162.
[34] Tribble, C. (2015). Teaching and language corpora: Perspectives from a personal journey. In A. Leńko-Szymańska and A. Boulton (Eds.), Multiple affordances of language corpora for data-driven learning (pp. 37-62). Amsterdam: John Benjamins.

[35] Uchibori, A., Chujo, K., and Hasegawa, S. (2006). Toward better grammar instruction: Bridging the gap between high school textbooks and TOEIC. Asian EFL Journal, 8(2), $228-253$.

[36] Utiyama, M., and Isahara, H. (2003). Reliable measures for aligning Japanese-English news articles and sentences. Proceedings of the 41st Annual Meeting of the Association for Computational Linguistics (pp. 72-79). 